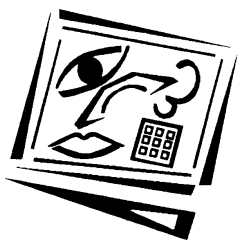

\title{
Academic and student use of a learning management system: Implications for quality
}

Debbi Weaver

Swinburne University of Technology

\author{
Christine Spratt and Chenicheri Sid Nair \\ Monash University
}

\begin{abstract}
Many higher education institutions have implemented a learning management system (LMS) to manage online learning and teaching, with varying levels of support provided to staff and students, but often there is little subsequent investigation into the quality of the online sites or the use made of the support structures provided. This paper presents findings from an institutional survey investigating the use of WebCT by academic staff and students in their learning and teaching at a large Australian university. It was expected that student feedback would relate to technical and infrastructure issues, but instead, the survey elicited responses primarily on how WebCT was used in teaching and learning, indicating that quality control is a major issue for the University. Student opinions appear to reflect more the use of the technology made by teaching staff - students who have experienced a well-designed unit rich with resources, timely feedback and good interaction with staff reported a positive experience with the technology. Staff responses are more focused on the technical and administrative aspects of using WebCT rather than teaching issues. The findings in this paper have implications for quality teaching and learning with technology, and the way in which tertiary institutions support academic staff.
\end{abstract}

\section{Introduction}

The past decade has seen enormous growth in the use of learning management systems (LMS) in higher education institutions, with varying levels of support provided to staff and students during the implementation phases. This has, in theory at least, provided the potential for rich learning environments built on social constructivist theories and available to all students, both on campus and those studying at a distance (Hawkes \& Terry, 2003; Papasergiou, 2005: Ng, 2007). Much has been published about what constitutes good online teaching (Chickering \& Ehrmann, 1996; Oliver, 2003; Bates, 2005), and this literature has expanded with institutional interests in quality online learning environments (see for example Evans \& Nation, 2000; Oliver, 2003; McLoughlin \& Visser, 2003; Bates 2005). Holt \& Challis' (2007) recent paper investigated one institution's experience of implementing strategic change through an institutional policy imperative couched in terms of integrating 'wholly' online units in various undergraduate curricula. This is an interesting paper and is relevant to the research reported here for the insights it provides in demonstrating that institutional policy initiatives 'do not necessarily lead to straightforward, predictable, and unproblematic teaching and learning outcomes' (Holt \& Challis 2007, p. 130). We discuss this paper subsequently. 
Assessing quality in online teaching is problematic, both due to a lack of agreement over standards and criteria for assessing learning outcomes, and for mixed mode teaching, an inability to separate the learning that occurs online from that which occurs in other environments (Zhao, 2003). This study was a preliminary study attempting to ascertain key problem areas in online teaching and learning at a single institution, but the findings are relevant to other Australian universities struggling with the same or similar challenges.

This paper attempts to gain some insight into how staff and students use a LMS at Monash University in Australia. Monash is a very large institution, with over 53,000 students and campuses located in metropolitan Melbourne, in regional Victoria and two international campuses (in Malaysia and South Africa). Most students are enrolled at the metropolitan campuses, where there is a traditional and strong on campus pedagogical culture for its 53,000 students. Monash makes admirable claims about its interests in developing quality teaching and learning environments and using educational technologies to develop student centred flexible learning (see the Monash University Excellence and Diversity: Strategic Framework 2004-2008). Monash is also a research intensive university - indeed, Monash is part of a consortium of eight institutions known in the Australian higher education sector (there are 38 universities in Australia) as the 'Group of 8' (Go8) universities. Collectively, the Go8 universities receive over $70 \%$ of national competitive research grants and conduct over $60 \%$ of all Australian university research (http:/ / www.go8.edu.au/). This means essentially that its academic staff, like others across the sector, face competing demands on their time and intellectual energies in that they are expected to excel at both teaching and research.

In 2001, WebCT was introduced at Monash University as the institution-wide, centrally supported learning management system (LMS). Since then, there has been an exponential rise in the number of academic users of WebCT and the number of active WebCT units across the University (Weaver, 2003). Currently at Monash University, there are over 22,500 registered users of WebCT Vista and 6,400 units. With students often enrolled in multiple WebCT units, the total of live unit registrations exceeds 75,000 .

Adoption of WebCT by academic teaching staff was optional in all but one Faculty. The original intention was that the LMS would be voluntarily taken up first by the recognised 'early adopters', who would then be able to provide support for their colleagues, and that student demand would provide the main incentive for the remainder of the academic population. It was thought that mandating the use of WebCT early on may have alienated and disenfranchised many staff, but over time, these staff would become more comfortable with the idea and would voluntarily decide to incorporate online teaching into their curriculum.

During the planning and implementation phase of the 2001 project, high expectations were placed on the academic teaching staff - they were expected not only to be experts in their own discipline area, but were also expected to build their own online sites, regardless of their competence and confidence in using educational technologies or their capability as educational designers. Support was available in the form of a comprehensive staff development program (Weaver, 2006), online resource materials, extended hours helpdesk, and a small but highly experienced team of educational designers, willing to work with individual staff to design and develop their units. 
However, despite all these services being freely available and widely advertised through the University's central teaching and learning support centre, it was up to the academic teaching staff to approach the relevant providers, and the overall number of staff utilising the full range of these services remained relatively low. Given the size of Monash (approximately 2500 teaching staff), it was logistically impossible that more staff could be supported. Participation in staff development related to WebCT and online learning prior to commencing online teaching was voluntary, although one Faculty mandated staff development.

Similarly, students were required to use the new system, usually with little or no introduction. Induction of students was left to the teaching staff and the expected disparity in the range of tools and instructional designs used by different lecturers was evident - some chose to demonstrate their sites in a lecture environment, but for others who were teaching to predominantly off campus students, this was not an option, and any induction for students was conducted within the LMS environment.

During the implementation phase, no recommendations of teaching or design standards or quality control mechanisms were instituted, with the unsurprising outcome of online units of highly variable quality; the implications of this are discussed subsequently.

\section{Method}

There has not been any cross-Faculty investigation of the use of WebCT at Monash University since the initial project implementation, and only limited evaluation of online teaching within one or two Faculties.

The objectives of the project reported in this paper were to:

1. conduct institution-wide surveys of staff and students actively using WebCT to determine what use was being made of the LMS;

2. investigate which areas of online teaching with WebCT needed improvement or further investigation;

3. inform developments in the pedagogical applications of $W e b C T$, including quality improvement strategies in online learning environments and;

4. inform staff development and training initiatives related to WebCT specifically and online learning more broadly.

The principal method was an anonymous online survey. We acknowledge that quantitative surveys alone provide limited information, and the findings therefore may not include all perspectives (Hammond \& Wiriyapinit, 2005; Gilead, 2006); however this project was intended as a preliminary study, and (at the time of the study) further exploration into key areas of interest identified by the research was planned as an ongoing investigation.

Student and staff perceptions of WebCT were measured to establish what features of the LMS were being used in teaching and learning, and the experiences of the staff and students using these features. Two surveys were administered, one for students and the other for staff. The student survey comprised 56 quantitative items organised into three parts. The first part sought biographical information. Part two of the survey measured student usage of $W e b C T$, and the final part investigated the kind of support respondents sought in order to use WebCT successfully. The student survey also 
sought qualitative feedback in regard to support, and respondents' perceptions of additional features that could extend $W e b C T$ as a learning tool.

The staff survey comprised 27 quantitative items in four sections. The first section sought biographical information. The second section aimed to investigate training and support issues for WebCT, and section three investigated respondents' perceptions of using WebCT in their teaching. Section four measured respondents' experiences with WebCT, on a 5-point Likert scale. The staff survey also sought comments about their experiences using $W e b C T$ in their teaching.

20,000 students were identified as being enrolled in at least one active WebCT unit, and contacted via email and invited to participate in the research by completing the survey online. A total of 1314 students responded (a response rate of 6.6\%). Almost 2,500 academic staff who were known WebCT users were emailed and invited to participate in the research: 96 responded (3.8\% response rate). The poor response from academic staff was disappointing to the researchers (given that the invitations were only sent to staff who had chosen to adopt online teaching) and a major limitation of the study. Responses to web based surveys vary widely, with the global average being in the order of 30\% (Dommeyer et al, 2004). Responses to other surveys carried out by the Centre for Higher Education Quality at Monash vary from 2\% to 71\%, depending on the size and type of cohort. Descriptive statistical analysis was undertaken.

\section{Teaching with WebCT: Staff perceptions}

The survey analysis revealed that $70 \%$ of academic staff (67 of 96 respondents) experienced problems with $\mathrm{WebCT}$ and that these were largely software related (staff believed the tool was 'clunky', 'slow' and 'awkward to upload files'). Technical and support related concerns rated highly as areas of dissatisfaction. Academic staff seemed to require more local IT support than was available to them. Despite this, staff valued the LMS in so far as they identified the communications related tools as the most beneficial for their teaching - 60\% (57 of 96 respondents) used at least one of the available communication tools). Furthermore, $40 \%$ of academic staff (39 of 96 respondents) used the assessment management tools.

Given the demands of academic life noted earlier, it was not surprising that the survey revealed a perceived increased workload associated with using technology in teaching: academic staff reported that the major time consuming aspects of WebCT were related not so much to their teaching but rather to technical and administrative issues. Similar concerns have been reported by staff at other institutions (e.g. Garrote \& Pettersson, 2007).

Interestingly, the kinds of support that academic staff accessed remained 'local', with assistance from colleagues as the most common avenue reported by the majority of staff $(55.3 \%)$. While $47 \%$ of respondents attended the centrally supported WebCT workshops to familiarise themselves with WebCT, it was noteworthy that $65.6 \%$ of respondents reported that they learnt about WebCT by working it out for themselves.

The survey also determined that staff required ongoing help in specific areas on an as needed basis, as well as rapid online technical assistance (Table 1). While almost half the respondents were satisfied with the level of support available to them, a substantial proportion $(43 \%)$ indicated they required more support. The survey also identified that 
academic users of WebCT were concerned about support for new versions of WebCT (at the time of the surveys, the University was preparing to move to WebCT Vista). Importantly, staff also identified their interest in seeking advice on good online teaching practices.

Table 1: Ongoing help required to support use of WebCT

\begin{tabular}{|l|c|c|}
\hline & Number & Percentage (\%) \\
\hline Specific training as I require it & 58 & 60.4 \\
\hline Online technical assistance & 57 & 59.4 \\
\hline Assistance in migration to new versions of software & 48 & 50.0 \\
\hline Advice on good practice in online teaching and learning & 44 & 45.8 \\
\hline Support to ease my workload & 39 & 40.6 \\
\hline Specific advice on particular learning issues & 27 & 28.1 \\
\hline Support in managing large classes & 27 & 28.1 \\
\hline Other & 13 & 13.5 \\
\hline
\end{tabular}

Other ongoing support needs, identified apart from those listed in Table 1, were help specifically with automatic assessment, quality online help facility, local support, the availability of synchronous chat lines (at the time of the survey, the LMS Chat tool was disabled) and decision makers taking into consideration pedagogical concerns.

\section{Learning with WebCT: Student perceptions}

It was reassuring that the survey revealed a student cohort generally positive and satisfied with their experience of using WebCT (Table 2). Students reported few technical problems with using the LMS and those who did managed to find solutions early in their use of WebCT.

Table 2: Difficulty experienced in learning to use WebCT

\begin{tabular}{|l|c|c|}
\hline & Number & Percentage (\%) \\
\hline Major difficulties & 59 & 4.5 \\
\hline Minor difficulties & 334 & 25.5 \\
\hline Generally easy to learn & 675 & 51.6 \\
\hline Always easy to learn & 240 & 18.4 \\
\hline
\end{tabular}

With respect to resources used by students to learn WebCT, half of all students reported learning how to use WebCT by themselves (Table 3), and a further 23\% received an introduction from their lecturer or tutor. Only $31 \%$ of students were aware of the existence of the CeLTS helpdesk (Table 4), with very few of these utilising this service, and even fewer being aware of the online student manuals. While most students were aware of the existence of ITS and Faculty helpdesks, a large proportion of students were unaware of the available support services.

Table 3: Resources utilised to learn WebCT

\begin{tabular}{|l|c|c|}
\hline & Number & Percentage (\%) \\
\hline Worked it out myself as I went & 969 & 50.9 \\
\hline My lecturer or tutor provided an introduction to the unit & 439 & 23.1 \\
\hline Other students helped me to get started & 162 & 8.5 \\
\hline Consulted online resources & 91 & 4.8 \\
\hline Lecturer or tutor helped me to get started & 89 & 4.7 \\
\hline Completed a preliminary online exercise & 70 & 3.7 \\
\hline Consulted helpdesk staff & 33 & 1.7 \\
\hline Other & 49 & 2.6 \\
\hline
\end{tabular}


Table 4: Awareness of support services

\begin{tabular}{|l|c|c|c|c|}
\cline { 2 - 5 } \multicolumn{1}{c|}{} & \multicolumn{2}{c|}{ Support services } & \multicolumn{2}{c|}{ No } \\
\cline { 2 - 5 } \multicolumn{1}{c|}{} & Number & Percent (\%) & Number & Percent (\%) \\
\hline ITS Helpdesk & 1007 & 77.5 & 292 & 22.5 \\
\hline Online help functions within WebCT & 791 & 60.8 & 511 & 39.2 \\
\hline Faculty or School helpdesk & 731 & 56.4 & 565 & 43.6 \\
\hline Central WebCT helpdesk & 402 & 31.1 & 891 & 68.9 \\
\hline Online student manuals & 327 & 25.2 & 969 & 74.8 \\
\hline
\end{tabular}

Students in the study who experienced a unit rich with interesting and relevant resources that reflected sound educational design, including opportunities for timely feedback and, importantly, interaction with their teachers, reported their experience with the technology positively. A substantial proportion reported sites that had minimal feedback, limited opportunities for interaction with their teachers, hyperlinks that did not work, and old or outdated information (These factors were indicated in response to the open ended questions on the survey).

The qualitative data revealed students' considerable dissatisfaction with the majority of the sites they were exposed to for learning support. Students believed that 'it [online teaching] works well when the lecturer wants to make it work well'; however if 'content was not always up to date or complete', online teaching was perceived as poor. Further, students recognise good teaching and can gauge the potential of the existing learning tools in WebCT; as one stated 'most of the tools mentioned would be useful, but have not been used by our course designers' and, for example, the 'calendar is only useful if it is current. If the calendar is from the previous year, then it is extremely unhelpful!' Furthermore the qualitative data indicated students valued and wanted easy access to online lecture notes (both for printing and saving files), and appropriate feedback on their progress in a timely manner. Analysis of the qualitative data also revealed that students who underwent some form of introduction to their particular WebCT site were more successful in using the technology and clearer about what was expected of them in the unit.

The student responses raise major issues about the quality of the online sites - both issues of teaching quality (appropriate teaching activities, level of interaction and feedback) and either poor use of technology (little use of available features, inappropriate file types uploaded, large file sizes) or lack of appropriate maintenance (broken links, outdated information). At the time of this study, no routine checks of WebCT sites were conducted prior to release to students. Following on from this study, a service was implemented where the WebCT helpdesk staff offered to conduct technical and maintenance evaluations of sites on request - however very few teaching staff took advantage of this opportunity. There is a growing evidence based literature (see for example Oliver, 2003; Laurillard, 2002; Armatas, Holt \& Rice, 2004) which supports our view that improving the quality of online teaching is a major challenge for Monash University and is a major imperative across the sector in Australia and internationally.

In analysing responses to the open ended questions from both staff and students, it was apparent that many staff had difficulty in maintaining their WebCT sites with current and relevant information. Student feedback indicated the primary areas of concern were with the many broken links and outdated materials, including extreme cases of calendar entries referring to dates from two years previous. Staff comments in 
this area were focused either on the lack of local IT support to help them maintain these sites, or lack of time to spend in online teaching.

\section{Discussion of findings}

In this study students and staff appeared to have contrasting priorities: academic teachers were more concerned with technical aspects and workload issues, and students were more concerned with the quality of the online teaching, which was reflected in their perception that their teachers were not engaged with them in what they believed ought to have been an interactive learning environment. The student survey data revealed that students were dissatisfied with poorly designed and maintained sites, rather than the lack of a site; this suggests that quality online learning approaches are an important adjunct to student learning, and if quality cannot be assured then online learning may be of little value.

Our study revealed that academic staff perceive that online teaching necessarily makes demands on workload and that staff require assistance with the technical and administrative tasks associated with using WebCT. This presumes that teaching staff may then be able to spend more time developing their skills and expertise in online learning and teaching. The provision of various forms of 'support' for staff who are less comfortable with using the technology may be the only way to encourage more engagement with their online students.

At Monash University at the time of our study a number of Faculties and Schools had mandated the inclusion of an online component for units of study; this however is not institutional policy. Student responses identified that in these circumstances, the online experience was frequently less satisfactory than when online teaching was a choice of the lecturer.

In contrast to our very broadly based survey research, Holt \& Challis' (2007) insightful paper presented a qualitatively informed case study report of an institutional initiative to integrate wholly online units across a number of diverse curriculum areas. Their research was undertaken in a well-established, internationally recognised distance education institution which differs considerably from Monash as the research intensive institution with a more traditional culture of campus based pedagogies described earlier. Holt and Challis (2007) have gone further in theorising and intellectualising the pedagogies associated with the implementation of 'wholly online units' at their university. While we do not wish to compare our results with theirs, perhaps we can say that the Monash experience reported in this paper supports, to some degree, their findings; that policy imperatives have meaning only in the way they are enacted in practice.

In this study the strong student response regarding their perceptions of the poor quality of much of the online teaching suggests that further strategies to encourage improved teaching must be considered. Initiatives such as local development grants, institutional showcases of exemplar sites (e.g. Designing Electronic Learning \& Teaching Approaches (DELTA), Brack et al, 2005), and awards recognising excellence in online teaching can encourage some staff to become more engaged with their online teaching, but may not reach the majority of staff. These initiatives are more likely to attract interest from the 'early adopters' of technology, whereas the major challenge is encouraging more interaction from the 'mainstream majority' of staff (Weaver, 2006). 
Moreover, a more determined policy initiative such as that described by Holt \& Challis (2007) may be needed for Monash to effect the kind of dramatic improvement in the quality of online pedagogies that this study seems to indicate is needed.

Ongoing seminars, presentations and staff development workshops can help demonstrate different strategies used by staff to engage students in online teaching, but these events need to be relevant to the targeted audience, and to be offered at times and venues convenient to the staff. Previous offerings of these events have been poorly attended at Monash, and often, attract interest largely from the early adopters - this is problematic for it becomes a case of 'preaching to the converted'. Staff requests for 'just in time' support must be accommodated, either by face to face sessions, by appropriate online resources, or a combination of both (Weaver, 2006; Wilson \& Stacey, 2004).

Issues of student training were also raised. Students are often unaware of features in WebCT or how to use the existing tools effectively, and are largely unaware of existing support services available to them. The WebCT Helpdesk staff offer to conduct brief introductions on using WebCT in lectures or other classes, but it appears that few staff are either aware of this service, or are using it for their students.

Arising from these findings, a series of recommendations was submitted to senior staff and policy making bodies within the University (including all Faculty Deans). These recommendations suggested further and ongoing evaluation of online teaching within Faculties, greater encouragement for staff to actively interact with their students online, and more appropriate use of the online technology. The key message was that online teaching should be more than a static WebCT site. In particular, Faculties and Schools were encouraged to provide additional technical support for staff, particularly where online teaching is mandated, and existing staff and student support services should be promoted more widely.

It is important to note that the research which informed this study was unfunded and conducted largely out of the personal interests of the co-authors. While a formal report was submitted to various stakeholders, it was our sense that in the absence of a committee structure through which the survey was conducted, we had little real expectation that recommendations might be systematically implemented. Since the study however, there has been considerable change in the governance and other structures that manage and foster e-learning at Monash. At the time of publication a new Educational Technology Framework has been developed through a newly formed Educational Technology Committee which is a Sub-Committee of the University's Learning and Teaching Quality Committee (http://www.calt.monash.edu.au/ Quality/ETC). It may be that now is the time for Monash to address more systematically its commitment and support for e-learning pedagogies institutionally.

Given these developments and the findings reported here, other avenues for research in the field present themselves for Monash. Potential research questions might include:

- What is the impact of policy initiatives on e-learning and teaching pedagogies in a research intensive university?

- How does blended learning influence student learning outcomes?

- What influences academic staff to sustain their use e-learning strategies? 


\section{Conclusion}

Our findings illustrate that online learning and teaching presents many challenges to Monash University specifically and the higher education sector broadly. These issues are not new to those of us teaching and researching the field of online learning (see for example Evans \& Nation, 2000; Spratt, 2003; Naidu, 2004; Oliver, 2005; Holt \& Challis 2007). Conole (2004) in a paper titled 'E-learning: The hype and the reality' suggests that if we believe that 'e-learning is transforming education', as some would have it, then we are sadly deluded. She argues that 'e-learning is still marginal in the lives of most academics with technology being used for little more than acting as a content repository'. While they may make some contribution to student learning, online learning environments that restrict themselves to delivering static resources do not characterise quality online learning environments (Oliver, 2003) nor do they take account of learner characteristics which may influence learning (Armatas, Holt \& Rice, 2003).

We believe that to be effective, tertiary education should engage learners as active participants in their learning. Achieving this means offering learners opportunities for interaction in ways that can promote change and growth in the learner's conception of knowledge. Such pedagogies aim to encourage learners to become autonomous lifelong learners, capable of problem solving and critical thinking, and to move them from being passive recipients of information and knowledge to being active, enthusiastic learners and knowledge creators. Moreover, tertiary pedagogy is concerned with building meaningful learning relationships between learners and teachers, and learners and their peers. It involves encouraging collaboration in learning as well as cooperation in learning; the appropriation of technology for teaching suggests great opportunities for the promotion of innovative and interactive quality e-learning environments.

While the major findings of this study indicated evidence of a teacher centred, content focused e-learning approach, both staff and students indicated willingness to learn and engage more in the online environment. Since the completion of this study, the policy discourse at Monash has become less concerned with the appropriation of educational technologies to promote Monash as a provider of 'virtual education' where student centred flexible and online learning might differentiate Monash from its competitors, and more concerned with developing educational policies that develop Monash's on campus expertise. While there remains an emphasis on internationalisation and improving the campus based experience of students, information technologies are perceived more as supporting administration functions and supporting fac to face teaching.

In a review of institutional AUQA quality audits, Martin (2003, p. 19) noted that 'in the main, there was comparatively little attention paid to pedagogy' and in relation to flexible online learning, that the Audit Reports did not reveal any particular focus 'apart from a need to ensure overall co-ordination of developments and parity of standards across different modes of delivery' (p.18). Further of relevance for this paper was Martin's (2003) finding that institutional support for new teaching staff across the reviewed institutions needed improvement, as did opportunities for professional development for teaching for permanent academic staff. While appreciating that the AUQA audits are concerned broadly with quality assurance issues in complex institutions, the apparent lack of attention to teaching related indicators of quality is 
notable. Moreover, Martin (2003, p. 33) highlights what she calls 'outreach' teaching and describes as 'off shore campuses, partnerships and external delivery' as a key area that 'presents challenges for maintaining consistency of standards, of resourcing and of planning'.

Information technologies are now routinely called upon to support Martin's (2003) 'outreach teaching'. Further, the policy documentation of higher education institutions includes information technologies as a key strategic goal to support initiatives in advancing student centred flexible learning, and improving the quality of teaching. However, if the way in which the majority of WebCT sites are perceived by students in this study is any indication, this objective is not being achieved. Students demand more than a repository dump - they want and need active and enthusiastic engagement from their teachers. Our results indicate that, due to a perceived lack of institutional support and adequate resourcing, many staff are forced to adopt a teacher centred approach in their online teaching. Universities need to pay more attention to the institution's key stakeholders, students, and support academic staff and to advance the widely recognised potential of online learning. In other words, if academic teaching staff are to engage with technology in ways that encourage them to innovate then institutions must 'make such efforts to enhance the learning of their students a high priority and back this in practice as well as in their rhetoric (Hannan, 2005, p. 984).

\section{References}

Armatas, C., Holt, D. \& Rice, M. (2003). Impacts of an online resource-based learning environment - Does one size fit all? Distance Education, 24(2), 141-158.

Bates, T. (2005). Technology, e-learning and distance education. London: Routledge.

Brack, C., Samarawickrema, G. \& Benson, R. (2005). Technology advances: Transforming university teaching through professional development. In A. Brew \& C. Asmar, C. (Eds), Higher Education in a changing world: Research and Development in Higher Education, Volume 28. Sydney: Thunder Press. pp. 50-59.

http:// www.itl.usyd.edu.au/herdsa2005/pdf/refereed/paper_306.pdf

Chickering, A. \& Ehrmann, SC (1996). Implementing the seven principles: Technology as lever. AAHE Bulletin, October, 3-6. [viewed Oct 2006, verified 23 Dec 2007] http: / / www.tltgroup.org/programs/seven.html

Conole, G. (2004). E-learning: The hype and the reality. Journal of Interactive Media in Education, 2004(12). http: / / www-jime.open.ac.uk/2004/12/

Dommeyer, C.J., Baum, P., Hanna, R.W. \& Chapman, K.S. (2004). Gathering faculty teaching evaluations by in-class and online surveys: Their effects on response rates and evaluations. Assessment \& Evaluation in Higher Education, 29(5), 611-623.

Evans, T. \& Nation, D. (2000). Understanding changes to university teaching. In T. Evans \& D. Nation (Eds.), Changing university teaching: Reflections on creating educational technologies. Kogan Page, London, pp.160-175.

Garrote, R. \& Pettersson, T. (2007). Lecturers' attitudes about the use of learning management systems in engineering education: A Swedish case study. Australasian Journal of Educational Technology, 23(3), 327-349. http:/ / www.ascilite.org.au/ajet/ ajet23 / garrote.html

Gilead, Y. (2006). Beyond the classroom: WebCT and learning Modern Hebrew. Australasian Journal of Educational Technology, 22(3), 416-438. http:/ / www.ascilite.org.au/ajet/ajet22/gilead.html 
Hammond, M. \& Wiriyapinit, M. (2005). Learning through online discussion: A case of triangulation in research. Australasian Journal of Educational Technology, 21(3), 283-302. http:/ / www.ascilite.org.au/ajet/ajet21/hammond.html

Hannan, A. (2005). Innovating in higher education: Contexts for change in learning technology. British Journal of Educational Technology, 36(6), 975-985.

Hawkes, M. \& Dennis, H. (2003). Supporting and assessing online interactions in higher education. Educational Technology, 43(4), 52-56.

Holt, D. \& Challis, D. (2007). From policy to practice: One university's experience of implementing strategic change through wholly online teaching and learning. Australasian Journal of Educational Technology, 23(1), 110-131. http: / / www.ascilite.org.au/ajet/ajet23/holt.html

Laurillard, D. (2002). Rethinking university teaching: A framework for the effective use of educational technologies. Routledge, London.

Martin, A. (2003). 2002 Institutional audit reports: Analysis and comment. AUQA Occasional Papers 1, Melbourne, Australian Universities Quality Agency. http: / / www.auqa.edu.au/files/publications / anne_martin_report_final.pdf

McLoughlin, C. \& Viser, T. (2003). Quality e-Learning: Are there universal indicators? In Sustaining Quality Learning Environments. Proceedings ODLAA 2003. Canberra, 1-3 October. [verified 23 Dec 2007] http: / / odlaa.une.edu.au / publications / 2003Proceedings/pdfs / mclougv.pdf

Monash University (2004). Excellence and Diversity: Strategic Framework 2004-2008. [viewed Oct 2006, verified 23 Dec 2007] http:/ / www.monash.edu.au/about/monashdirections/excellence.html

Naidu, S. (2004). Trends in faculty use and perceptions of eLearning. Asian Journal of Distance Education, 2(2) [viewed Oct 2006, not found 23 Dec 2007] http: / / www.asianjde.org/

$\mathrm{Ng}$, K. C. (2007). Replacing face-to-face tutorials by synchronous online technologies: Challenges and pedagogical implication. International Review of Research in Open and Distance Learning, 8(1), 1-15. [verified 23 Dec 2007] http:/ / www.irrodl.org/index.php/irrodl/article/view/335/764

Oliver, R. (2003). Exploring benchmarks and standards for assuring quality online teaching and learning in higher education. Keynote address to the 16th Open and Distance Learning Association of Australasia, Conference Proceedings: Sustaining Quality Learning Environments. Canberra, October 1-3. [verified 23 Dec 2007] http: / / www.odlaa.org/ publications/2003Proceedings/pdfs/oliver.pdf

Oliver, R. (2005). Quality assurance and e-learning: Blue skies and pragmatism. ALT-J: Research in Learning Technology, 13(3), 173-187.

Papasergiou, M. (2005). Management systems as tools for the creation of online learning environments: Evaluation from a social constructivist perspective and implications for their design. International Journal on E-Learning, 5(4), 593-622.

Spratt, C. (2003). Technology innovators and structures of indifference in higher education. 16th Open and Distance Learning Association of Australasia, Conference Proceedings: Sustaining Quality Learning Environments, Canberra, 1-3 October. http: / / www.odlaa.org/publications/2003Proceedings/pdfs/ spratt.pdf

Weaver, D. (2006). The challenges facing staff development in promoting quality online teaching. International Journal on E-Learning, 5(2), 275-286. Chesapeake, VA: AACE. 
Weaver, D. A. (2003). Evolution of a staff development program in promoting quality online teaching. In Interact, Integrate, Impact: Proceedings ASCILITE Conference. Adelaide, 7-10 December. p 532-540.

http: / / www.ascilite.org.au/conferences/adelaide03/docs/pdf/532.pdf

Wilson, G. \& Stacey, E. (2004). Online interaction impacts on learning: Teaching the teachers to teach online. Australasian Journal of Educational Technology, 20(1), 33-48.

http:/ / www.ascilite.org.au/ajet/ajet20/wilson.html

Zhao. F. (2003). Enhancing the quality of online higher education through measurement. Quality Assurance in Education, 11(4), 214-221.

Debbi Weaver is currently an Educational Development Advisor at Swinburne University of Technology. Previously, she was a lecturer in e-learning at Monash University, responsible for the development and delivery of academic staff training in the use of WebCT.

Christine Spratt [Christine.Spratt@ranzcp.org] is currently Education and Curriculum Advisor at the Royal Australian and New Zealand College of Psychiatrists. Previously she was Senior Lecturer (Strategic Development Support) at Monash University where she was responsible for coordinating a range of institutional teaching and learning initiatives.

Associate Professor Chenicheri Sid Nair [Sid.Nair@adm.monash.edu.au] is a Quality Adviser with the Centre for Higher Education Quality at Monash University. Currently, he heads up the evaluation section for the Centre.

Address for correspondence: Debbi Weaver, Academic Development \& Support, Swinburne University of Technology, Locked Bag 218, Lilydale, Vic 3140, Australia. Email: dweaver@swin.edu.au 